\title{
Las relaciones Brasil-China en el siglo XXI
}

\author{
Luís Antonio Paulino \\ luis.paulino@unesp.br \\ Universidade Estadual Paulista
}

Recibido: 19/08/2020. Aceptado: 23/11/2020

Resumen: En 2020, Brasil celebra 46 años de relaciones diplomáticas con China, pero la historia de las relaciones entre los dos países es mucho más antigua y se remonta al período colonial. Las relaciones oficiales Brasil-China comenzaron a fines del siglo XIX, pero solo en el siglo XX, especialmente después de 1974, cuando los países reanudaron las relaciones diplomáticas, se hicieron más sólidas. Sin embargo, fue recién en el siglo XXI, especialmente después de 2003, que las relaciones bilaterales se intensificaron y alcanzaron el nivel actual de relaciones maduras. En 2018, la elección del presidente Jair Bolsonaro marcó un nuevo punto de inflexión en la historia reciente de las relaciones entre Brasil y China.

Palabras clave: relaciones Brasil-China; diplomacia; comercio; inversión extranjera.

* Cómo citar este artículo: Paulino, L. (2020). Las relaciones Brasil-China en el Siglo XXI. Relaciones Internacionales, 29(59), 111. https://doi.org/10.24215/23142766e111

Editor: Juan Alberto Rial, Instituto de Relaciones Internacionales Facultad de Ciencias Jurídicas y Sociales (Universidad Nacional de La Plata)
Entidad editora: Relaciones

Internacionales, es una publicación del Instituto de Relaciones Internacionales (Facultad de Ciencias Jurídicas y Sociales (Universidad Nacional de La Plata Argentina)

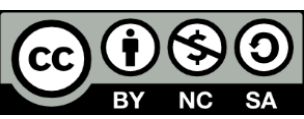

Reconocimiento-NoComercial Compartirlgual 4.0 Internacional (CC BY-NC-SA 4.0) 


\title{
Brazil-China Relations in the 21st Century
}

\section{Luís Antonio Paulino ${ }^{1}$}

\begin{abstract}
In 2020, Brazil celebrates 46 years of diplomatic relations with China, but the history of relations between these two countries is much older and dates back to colonial times. Official Brazil-China relations began in the late 19th century, but in the 20th century, especially after 1974, these countries resumed diplomatic relations and these relations became more robust. However, it was only in the 21st century, especially after 2003, that bilateral relations intensified, reaching their current mature level. In 2018, the election of President Jair Bolsonaro marked a new turning point in the recent history of Brazil-China relations.
\end{abstract}

Keywords: Brazil-China relations; diplomacy; trade; foreign investment.

\section{Brazil-China Relations in the 21st Century}

Resumo: O Brasil comemora, em 2020, 46 anos de relações diplomáticas com a China, mas a história das relações entre os dois países é muito mais antiga e remonta ao período colonial. As relações oficiais Brasil-China tiveram início ainda no final do século XIX, mas apenas no século XX, especialmente depois de 1974, quando os países reataram as relações diplomáticas, se tornaram mais robustas. Entretanto, foi somente no século $\mathrm{XXI}$, especialmente depois de 2003, que as relações bilaterais se intensificaram, alcançando o atual patamar de relações maduras. Em 2018, a eleição do presidente Jair Bolsonaro, marcou um novo ponto de inflexão na história recente das relações Brasil-China

Palavras-chave: relações Brasil-China; diplomacia; comércio; investimento estrangeiro.

1 Profesor de la Universidade Estadual Paulista (Unesp) y director del Instituto Confucio de la Unesp. Fue Asesor Especial del Ministerio de Hacienda (2003), Secretario Ejecutivo de la Secretaría de Coordinación Política y Asuntos Institucionales de la Presidencia de la República de Brasil (2003-2005) y Jefe de Asesoramiento del Ministerio de Deportes (2012-2014). 


\section{Introducción}

La historia de las relaciones Brasil-China es casi tan antigua como el propio Brasil. Durante siglos, Brasil fue un punto de parada en la ruta marítima para los barcos portugueses y de otros países en su comercio entre Europa y Asia. El más importante producto de importación mundial en el siglo XVII fue la plata, que viajaba desde Potosí hasta Buenos Aires y era vendida por contrabandistas a comerciantes portugueses de la antigua Colonia de Sacramento y de Río de Janeiro, e iba desde allí no solo hasta Lisboa, sino también directamente a India y China (MACLEOD, 1999, p. 262).

Un importante punto de contacto entre Brasil y Asia fueron las posesiones portuguesas en el Este, especialmente Goa, en India, y Macao, en China. Como señalan SCOMAZZON y FRANCO (2020, p.237), "Las relaciones chino-brasileñas comenzaron en el período colonial, resultado no solo del intercambio de productos entre China y la América portuguesa, sino también debido ir y venir de comerciantes, religiosos, magistrados y aventureros, que circularon entre los dominios de ultramar de Lisboa".

Los primeros contactos oficiales entre Brasil y China tuvieron lugar a principios del siglo XIX, poco después de la transferencia de la capital del reino y la corte portuguesa a la ciudad de Río de Janeiro, en 1808. Por iniciativa del Conde de Linhares, 300 chinos llegaron a Brasil en 1810, para iniciar la cultura del té en el Jardín Botánico de Río de Janeiro (SCOMAZZON y FRANCO, 2020, p. 235).

La primera misión oficial brasileña en China tuvo lugar en el Segundo Imperio en un viaje de circunnavegación que duró 430 días, entre noviembre de 1879 y enero de 1881, y del que participaron 197 hombres, de los cuales solo 148 regresaron a Brasil, habiendo sufrido 49 bajas por muertes y deserciones (SCOMAZZON y FRANCO, 2020, p. 20). El motivo oficial de la misión era proponer un acuerdo de amistad, comercio y navegación con Brasil, pero el verdadero motivo era obtener el permiso del emperador chino para enviar trabajadores de China a Brasil, que, ante la perspectiva del fin de la esclavitud, enfrentaba en aquel momento el dilema de quién podría reemplazar a la mano de obra negra en los principales cultivos del país, especialmente en los cafetales. Como se sabe, el gobierno chino no estuvo de acuerdo con la propuesta, por temor a que estos trabajadores chinos pudieran ser esclavizados en Brasil, como ya había sucedido en Cuba y Perú.

En el siglo XX, los primeros contactos oficiales entre los dos países tuvieron lugar después de la fundación de la República Popular de China en 1949. La visita del entonces vicepresidente de Brasil, João Goulart, a China en 1961, cuando fue recibido por el gobierno y por el pueblo como un gran amigo de China, fue un punto culminante de esta fase inicial de las relaciones modernas entre Brasil y China. Después del establecimiento de la dictadura militar en Brasil, en 1964, las relaciones diplomáticas entre los dos países se interrumpieron durante diez años, pero se restablecieron ya en 1974, bajo la presidencia del general Ernesto Geisel.

Desde entonces, y especialmente después del restablecimiento de la democracia en Brasil, en 1985 , las relaciones diplomáticas, políticas y económicas entre los dos países han ido cobrando cada vez más impulso. 
BECARD (2011, p.31-41) clasifica la evolución de las relaciones Brasil-China en siglo XX en cinco etapas:

1. Relaciones embrionarias entre Brasil y China (1949-1974);

2. Fijación de las bases de las relaciones chino-brasileñas (1974-1990);

3. Crisis y nuevos desafíos en las relaciones chino-brasileñas (1990-1993);

4. Construcción de la asociación estratégica (1993-2003);

5. Relaciones maduras entre Brasil y China (2003 a 2011).

Para la autora, el hecho más importante de la primera etapa (1949-1974) fue la mencionada visita del vicepresidente de Brasil, João Goulart, a China, en agosto de 1961, en el marco de la llamada "política exterior independiente" implementada en el gobierno corto de Jânio Quadros (de enero a agosto de 1961).

En la segunda etapa (1974-1990), además de la reanudación de las relaciones diplomáticas en agosto de 1974, se destaca la firma del primer acuerdo comercial entre Brasil y China en 1978. Con el comienzo del proceso de reforma y apertura de China en el mismo año, y el comienzo del proceso de redemocratización en Brasil, las relaciones bilaterales ganaron mayor densidad. Según la autora, las posibilidades de ganancias concretas en las áreas económica, científica y tecnológica llevaron a la firma de más de 20 actos bilaterales con China a lo largo de la década de 1980 -incluidos los acuerdos básicos en las áreas de ciencia y tecnología, energía nuclear y cooperación cultural y educativo- que permitieron la institucionalización de las relaciones y el establecimiento de marco de referencia para acciones futuras (BECARD, 2011, p. 33).

Durante este período, hubo dos visitas de jefes de estado de Brasil a China: en junio de 1984, la visita del presidente João Figueiredo, el primer jefe de estado brasileño en visitar el país, y, en julio de 1988, la del presidente José Sarney. La propuesta de cooperación tecnológica entre los dos países, en vigor hasta hoy, para la construcción conjunta de satélites de teledetección conocidos como China-Brazil Earth Resource Satellite (CBERS) se lanzó en 1988. Brasil y China ya han lanzado satélites: el CBERS 1, en 1999; el CBERS 2, en 2003; el CBERS 2B, en 2007; el CBERS 3, en 2013; el CBERS 4, en 2014 y el CBERS 4A, en 2019.

La tercera etapa (1990-1993) fue un período de transición, marcado, a nivel internacional, por el final de la Guerra Fría y, a nivel nacional, por la apertura comercial y financiera promovida por el gobierno de Fernando Collor de Mello (1990-1992). En China, el proceso de apertura gana un nuevo impulso del histórico viaje de Deng Xiaoping al sur de China en 1992.

En la cuarta etapa (1993-2003), las relaciones bilaterales entre Brasil y China cobraron un nuevo impulso. En 1993, se firmó el acuerdo que elevaba la relación de los dos países a la condición de asociación estratégica. Durante este período, China comienza a definir sus objetivos más claramente en relación con Brasil y América del Sur.

En un discurso pronunciado el 6 de abril de 2001 en la sede de la CEPAL en Chile, el presidente Jiang Zemin destacó los principales parámetros que guiarían las relaciones entre 
China y América Latina: (1) fortalecer las relaciones políticas y aumentar el contacto directo y las consultas alto nivel entre los líderes chinos y su contraparte en América Latina; (2) aumentar las consultas y el apoyo mutuo sobre cuestiones internacionales de interés común, como el papel y la reforma de la ONU, la seguridad internacional, el establecimiento de un nuevo orden mundial, el progreso en la multipolaridad y la democratización de las relaciones internacionales; (3) ampliar la cooperación comercial, otorgando alta prioridad a la inversión recíproca y desarrollando la cooperación en alta tecnología; y (4) establecer relaciones cooperativas amplias y de largo plazo en otras áreas como cultura, educación, ciencia y tecnología y deportes (JIANG, 2010, v. 3, p. 236-237).

\section{Las relaciones Brasil-China en el siglo XXI}

En el siglo XXI, empieza así la quinta etapa, ya bajo la presidencia de Luiz Inácio Lula da Silva (2003-2010), que se extiende hasta 2017. Durante este período, se observó una reorientación en el sentido de intensificar las Ilamadas relaciones Sur-Sur, fortalecer la cooperación regional y diversificar las asociaciones comerciales de Brasil. Por el lado chino, su adhesión a la OMC en 2001 y el mantenimiento de un fuerte ritmo de crecimiento económico condujeron a una relación más estrecha con América Latina, principalmente debido a la creciente necesidad de China de importar productos agrícolas y, principalmente, recursos minerales, disponibles en grandes cantidades en la región. El continuo crecimiento del PIB chino a tasas anuales del orden del $10 \%$ en la primera década del siglo XXI comenzó a exigir la importación de cantidades cada vez mayores de recursos naturales, ya que era la base sobre la cual tuvo lugar la expansión de la economía china para hacerse más grande cada año. Como exportador de materias primas y petróleo, China se ha convertido en el mayor importador mundial de estos productos y ha comenzado a prestar mayor atención a América Latina y África. En 2015, de un total de US $\$ 1,68$ billones de importaciones, China importó US \$103,8 mil millones de América Latina y US \$ 70 mil millones de África, que, en conjunto, representan el $10 \%$ del total de las importaciones chinas (NATIONAL BUREAU OF STATISTICS OF CHINA, 2016).

Entre las iniciativas tomadas en este período cabe mencionar:

1. La creación, en 2004, de un nuevo marco institucional mediante el establecimiento de la Comisión Sino-Brasileña de Alto Nivel de Consulta y Cooperación (COSBAN), la instancia más alta de diálogo político entre los dos países;

2. La firma, en 2010, del Plan de Acción Conjunta Brasil-China (2010-2014) - PAC, que define objetivos, metas y directrices para la cooperación bilateral en sus diversos campos;

3. La elevación, en 2012, de las relaciones Brasil-China a la condición de Asociación Estratégica Global y el establecimiento del Diálogo Estratégico Global, a nivel de cancilleres;

4. La firma, en 2012, del Plan de Cooperación decenal para el período 2012-2021, (BARBOSA, 2012); y

5. La creación, en 2015 del Fondo de Cooperación Brasil-China para la Expansión de la Capacidad Productiva (ROSITO, 2020). 
La primera sección del Diálogo Estratégico Global tuvo lugar en abril de 2014, con motivo de la visita a Brasil del Ministro de Relaciones Exteriores, Wang Yi. Esta reunión también sirvió para definir acuerdos bilaterales, en vista de la 6a Cumbre BRICS, que fue realizada en Brasil, en julio de ese mismo año, seguida de la visita de Estado del presidente Xi Jinping. Además de la frecuencia anual de secciones Diálogo Estratégico Global (DEG) alternativamente en cada país, también se decidió que se celebrarían reuniones de diálogo sectoriales, que abarcarían temas como África, América Latina y el Caribe, Asia, Oriente Medio, Estados Unidos, derechos humanos, políticas sociales, planificación y diplomacia.

La cooperación científica, educativa y cultural también ocupa un lugar importante en la agenda bilateral, incluidos temas como la cooperación espacial, la biotecnología aplicada a la agricultura y la biomedicina, la nanotecnología, el cambio climático, las energías renovables, la bioenergía, las tecnologías agrícolas y forestales, la tecnología de la información, industrias creativas, entre otras. Todos estos temas forman parte del Plan de acción decenal (2012-2021). En el área de la educación, se profundizaron los intercambios académicos y educativos, mediante la inclusión de China en el "Programa de Ciencia sin Fronteras" y la instalación de los Institutos Confucio en Brasil.

Cabe señalar incluso que, durante este período, las relaciones Brasil-China también avanzaron en la dirección de una mayor cooperación internacional en temas de interés común. Además de los foros multilaterales tradicionales, como la ONU, el Fondo Monetario Internacional (FMI) y la Organización Mundial del Comercio (OMC), donde los dos países buscaban coordinar sus actividades, Brasil y China han establecido nuevas instituciones de cooperación con otros países en desarrollo, especialmente aquellos destinados a reunir a los grandes países en desarrollo en torno a intereses comunes, como el caso del grupo diplomático BRICS, el Banco de los BRICS, el Foro China-CELAC y el Banco Asiático de Inversión en Infraestructura ( AIIB), de los cuales Brasil es también uno de los socios fundadores.

\section{2018-2020: nuevos cambios y turbulencias en las relaciones bilaterales Brasil-China}

La elección del presidente Jair Bolsonaro en noviembre de 2018 representó un nuevo punto de inflexión en las relaciones políticas y diplomáticas entre Brasil y China. Aún como candidato, en 2018, el actual presidente brasileño adoptó una serie de actitudes que sugerían que las relaciones entre Brasil y China no serían tan fluidas si fuera elegido presidente de Brasil. En marzo de 2018, Bolsonaro realizó una visita a Taiwán y se reunió con la líder de la provincia china, Tsai Ing-wen. En esa ocasión, Bolsonaro declaró que "solo por el hecho de que hicimos un viaje a Israel, Estados Unidos, Japón, Corea y Taiwán, estamos mostrando con quién queremos ser amigos, uniéndonos con buenas personas, personas que piensan en su país" (MAGALHÃES, 2018).

La actitud irrespetuosa de Bolsonaro hacia China generó una reacción inmediata del gobierno chino, que consideró la visita oficial a Taiwán de un parlamentario brasileño y candidato a la presidencia de la República como una afrenta a la soberanía nacional china. Además de las protestas formales con el gobierno brasileño, varios periódicos chinos, como el 
China Daily y el Global Times, publicaron editoriales duras, en las que afirmaban que tales actitudes podrían tener consecuencias negativas para Brasil, que tiene su principal mercado de exportación en China.

Aún como candidato presidencial, en octubre de 2019, en una entrevista con una cadena de televisión local, Bolsonaro declaró: "China está comprando a Brasil. ¿Vas a dejar nuestra energía en manos de los chinos? (POLITO, 2019).

Poco después de ser elegido, el presidente Bolsonaro moderó su discurso agresivo hacia China, pero aún mostró reservas sobre la presencia de inversores chinos en Brasil. En una entrevista, el 5 de noviembre de 2018, después de recibir al embajador chino en Brasil, Li Jinzhang, Bolsonaro declaró que estaba interesado en aumentar los negocios con China, pero que "todos los países pueden comprar en Brasil, pero no comprar a Brasil" (PENNAFORT, 2018).

La presión del sector agroindustrial brasileño -una de las principales bases de apoyo político de Bolsonaro- que depende fuertemente del mercado chino, su mayor cliente, contribuyó al cambio en el discurso del presidente en relación con China. Solo para tener una idea de la importancia de China para este sector, entre 2000 y 2020, "las importaciones chinas saltaron del $2 \%$ al $35 \%$ de la canasta de exportación de agronegocios brasileña, convirtiendo a China en el principal cliente global de Brasil. Los agronegocios representan la mitad de las exportaciones totales de Brasil a China" (JANK, GUO y MIRANDA, 2020).

En marzo de 2019, el presidente brasileño, que unos meses antes había acusado a China de querer comprar Brasil, anunció que viajaría a China en la segunda mitad de ese año en busca de negocios e inversiones y que el presidente Xi Jinping vendría a Brasil en noviembre para la cumbre BRICS. "Queremos acercarnos al mundo entero, desarrollar nuestro comercio, abrir nuestras fronteras", declaró en ese momento.

En mayo de 2019, el vicepresidente de Brasil, general Hamilton Mourão, realizó una visita de cinco días a China. El objetivo era deshacer la mala impresión que los comentarios hechos por Jair Bolsonaro, antes de ser elegido, habían tenido en el gobierno chino. El propósito del viaje fue transmitir el mensaje de que Brasil considera a China como un socio importante. El viaje también sirvió para reactivar la instancia más alta de diálogo bilateral, la Comisión China-Brasileña de Alto Nivel de Consulta y Cooperación (Cosban), que se había paralizado desde 2015.

El vicepresidente brasileño fue recibido en China con honores del jefe de estado, en una clara demostración de que, a pesar de los ataques del presidente brasileño, el gobierno chino valoraba toda la historia de las relaciones bilaterales entre los dos países, construidas durante décadas, y pretendía mantener las relaciones bilaterales a un alto nivel y, no menos importante, los negocios.

En octubre de 2019, el presidente brasileño finalmente realizó la visita a China. En la visita de dos días a China, el presidente brasileño se reunió con el presidente Xi Jinping, en el Gran Palacio del Pueblo, en Beijing. En la ocasión, declaró que "[e]staba esperando esta visita porque China es el principal socio comercio de Brasil y estoy muy interesado en fortalecer este 
comercio, así como en ampliar nuevos horizontes. Hoy podemos decir que una parte considerable de Brasil necesita a China, China también necesita a Brasil" (AGÊNCIA BRASIL, 2020). En la ocasión, se firmaron 25 acuerdos y memorandos de entendimiento en las áreas de política, ciencia y tecnología y educación, economía y comercio, energía y agricultura.

En noviembre de 2019, el presidente Xi Jinping llegó a Brasil por segunda vez para asistir a la cumbre BRICS. En la ocasión, el presidente chino tuvo una reunión paralela con el presidente brasileño y se anunciaron una serie de nuevos acuerdos. El gobierno chino sorprendió al gobierno brasileño al abrir la posibilidad de que las empresas estatales chinas inviertan más de US\$ 100 mil millones en obras de infraestructura en Brasil. Este valor es 10 veces mayor que todo lo que el gobierno brasileño ha asignado para inversiones en el presupuesto federal para 2020. También se firmó un acuerdo para el comercio de frutas (exportaciones de melones de Brasil a China e importaciones de peras chinas). Además, el gobierno chino ha acreditado a 13 mataderos brasileños más para exportar carne a China y se ha asociado con Petrobras en las subastas de petróleo en las áreas del pré-sal, lo que evitó que la subasta fracase por completo, ya que las otras compañías petroleras internacionales, especialmente, las empresas estadounidenses no estaban interesadas.

Según los informes, la participación de China en la subasta de petróleo fue el resultado de la propia solicitud de Bolsonaro al presidente chino en su visita a China en octubre pasado. Vale la pena mencionar que, en septiembre de 2020, el gobierno ya había acreditado otros 25 mataderos para exportar carne a China (MENDES Y ZAIA, 2020).

A pesar de todos los esfuerzos del gobierno chino y de importantes sectores del propio gobierno brasileño, como el Ministerio de Agricultura y la comunidad empresarial brasileña, especialmente los agronegocios, para normalizar las relaciones bilaterales entre China y Brasil, un grupo de personas cercanas al presidente -el llamado "núcleo ideológico del gobierno" - compuesto por sus hijos, su ministro de Relaciones Exteriores, Ernesto Araújo, su exministro de educación, Abraham Weintraub, y algunos de los ayudantes del presidente, continuaron haciendo ataques contra China en las redes sociales.

Con el inicio de la pandemia del Covid-19, este grupo de personas más directamente vinculadas al presidente comenzó a ponerse a coro con el presidente estadounidense Donald Trump, en sus irrazonables ataques contra China, acusándola de ser responsable de la pandemia.

En marzo de 2020, el diputado federal Eduardo Bolsonaro, uno de los hijos del presidente y presidente del comité de asuntos exteriores de la Cámara de Diputados, causó un nuevo incidente diplomático con China. El 18 de marzo, publicó un mensaje en las redes sociales en el que acusaba a China de ser responsable de la pandemia del Covid-19. Este ataque generó una respuesta inmediata de la embajada china en Brasil. El mismo día, y también en las redes sociales, el nuevo embajador en China en Brasil, Yang Wanming, declaró que: "La parte china repudia vehementemente las palabras del diputado y exige que las retire de inmediato y se disculpe con el pueblo chino" (Jornal Nacional, 2020). El embajador chino también compartió con seguidores mensajes de otros que criticaron a la familia Bolsonaro. Poco después, la embajada china en Brasil publicó una respuesta directamente en el perfil de Eduardo Bolsonaro: "Sus palabras son extremadamente irresponsables y suenan 
familiares. Siguen siendo una imitación de tus queridos amigos. Al regresar de Miami, desafortunadamente contrajo un virus mental, que está infectando las amistades entre nuestros pueblos" (JORNAL NACIONAL, 2020).

En las primeras horas del 19 de marzo, el presidente de la Cámara de Diputados, el diputado Rodrigo Maia, habló sobre el tema en la misma red social: "En nombre de la Cámara de Diputados, pido disculpas a China y al Embajador @wanmingyang por las palabras irreflexivas de diputado Eduardo Bolsonaro ". Solo en la tarde del 19 de marzo, el ministro de Asuntos Exteriores habló en defensa del gobierno y la familia Bolsonaro, diciendo que "es inaceptable que el embajador chino respalde o comparta una publicación ofensiva con el jefe de estado de Brasil y sus votantes". La misma noche del 19 de marzo, la Embajada de China emitió una nota que refuerza la protesta por la actitud, que llama irresponsable, del diputado Eduardo Bolsonaro. También afirmó que la parte china no aceptó la intermediación hecha por el canciller Ernesto Araújo y que esperaba las disculpas del congresista Eduardo Bolsonaro al pueblo chino.

El 20 de marzo, una importante cadena de televisión nacional (Bandeirantes), en su periódico vespertino, con una audiencia nacional, transmitió un editorial en el que llamaba al canciller Ernesto Araújo un idiota, inepto e incapaz, en una evidente manifestación de que el presidente Bolsonaro y su gobierno habían caído en completo descrédito en el país. El presidente, preocupado por las posibles consecuencias para su principal base de apoyo político (el sector de agronegocios), trató de minimizar el incidente y dijo que "todo esto es pasado, no hay ningún problema con China" (BITENCOURT y MURAKAWA, 2020).

El 21 de marzo, Bolsonaro intentó hablar personalmente con el presidente chino para apaciguar la situación, pero este se negó a atenderlo (Fernandes, 2020). El 22 de marzo, el presidente chino tomó la iniciativa de llamar a su colega brasileño. No se sabe lo que se discutió, pero el hecho es que los chinos ven al gobierno brasileño con creciente sospecha.

Zhou Zhiwei, director ejecutivo del Instituto de Estudios Latinoamericanos de la Academia China de Ciencias Sociales (ILAS-CASS), el organismo asesor oficial del gobierno chino dijo en un artículo publicado en el periódico Global Times el 20 de marzo que "[e]l actual gobierno brasileño es un seguidor ideológico de la administración Trump, pero ellos son oportunistas y de doble cara en términos de cooperación en el campo de la economía y el comercio con China" (WANG y LU, 2020).

Por si fuera poco todo lo que había sucedido en marzo, en abril de 2020 hubo dos nuevas provocaciones contra China por parte de los ministros del gobierno brasileño. El primero fue el ministro de Educación, Abraham Weintraub, quien hizo provocaciones racistas contra China en las redes sociales. En el segundo, el Ministro de Relaciones Exteriores, Ernesto Araújo, quien escribió un artículo delirante, que también publicó en las redes sociales, en el que asociaba la crisis del Covid-19 con un plan de dominación mundial de los comunistas liderados por los chinos en alianza con nada menos que la OMS.

Muchas personas han dicho que la avalancha de ataques contra China por parte de las altas autoridades brasileñas podría llevar a China a reducir sus compras en Brasil, a saber: soja, carne, pollo, petróleo y otros productos que constituyen nuestra canasta de exportación para ese país. Según el acuerdo firmado con Estados Unidos para poner fin a la guerra 
comercial, los chinos se comprometieron a realizar compras adicionales de productos agrícolas por un valor de $\mathbf{2 0 0}$ mil millones de dólares en el mercado estadounidense. Esto podría ser en detrimento de Brasil.

No creemos que China dé ese paso en forma de represalia política. Compran en Brasil porque lo necesitan y les interesa. Entre 2017 y 2018, la exportación de soja de Brasil a China aumentó de 53,8 a 68,8 mil millones de toneladas métricas y el valor exportado subió de US\$ 20.300 millones a US\$ 27.300 millones. Es decir, como consecuencia de la guerra comercial enre Estados Unidos y China, la exportación brasileña de soja a China aumentó 15 millones de toneladas métricas y rindió a Brasil US\$ 7 mil millones de dólares más con las ventas de soja a China.

Hace una década, el $38 \%$ de la soja que entraba en el mercado chino venía de Estados Unidos y el $34 \%$ de Brasil. Hoy, el $57 \%$ de la soja que abastece a China viene de Brasil, según la Administración General de la Aduanas de China (DUARTE, 2019).

En mayo de 2020, "las ventas al país asiático crecieron un 35,2\% en comparación con el mismo mes del año pasado, representando el $40,4 \%$ de las exportaciones, frente al $28,6 \%$ en mayo de 2019" (RIBEIRO, 2020). Los chinos saben que el gobierno de Bolsonaro es fugaz y que las relaciones entre Brasil y China tienen un significado estratégico a largo plazo para ambas partes.

Sin embargo, es necesario considerar que las relaciones políticas entre los gobiernos terminan teniendo una gran influencia en las decisiones de inversión privada. Gran parte de lo que se ha hecho en los últimos años en términos de comercio e inversión se ha producido debido a la buena relación entre los dos países y sus presidentes. Los empresarios observan las buenas relaciones políticas entre los dos países y se sienten más seguros para invertir.

Al atacar a China, el gobierno de Bolsonaro socava la confianza de los inversores chinos en Brasil. Al tomar sus decisiones de inversión, las empresas consideran todos los riesgos involucrados, incluido el riesgo político. Una relación bilateral en deterioro aumenta el riesgo político y no hay nada que el gobierno chino pueda hacer al respecto; nadie va a poner dinero en un país en el que no confía. Brasil, que había estado recibiendo alrededor de US\$ 60 mil millones en inversión extranjera directa en últimos años, en 2020, no recibirá mucho más de US\$ 20 mil millones. Esta caída se debe, en gran medida, a los efectos de la pandemia covid-19 en la economía mundial, pero se ve reforzada por la terrible imagen internacional del presidente brasileño.

\section{Bolsonaro convierte el $5 G$ en una disputa geopolítica}

El gobierno brasileño está a punto de tomar una decisión que podría ser decisiva sobre el futuro de las relaciones bilaterales entre China y Brasil en los próximos años. Esta es la subasta de frecuencias $5 \mathrm{G}$, telefonía móvil e internet, que también decidirá qué compañías suministrarán la estructura de la red $5 \mathrm{G}$ en Brasil.

Inicialmente programada para celebrarse en noviembre de 2020 , la subasta se pospuso para 2021. El gobierno brasileño está bajo una gran presión de los Estados Unidos para evitar que la compañía china Huawei, el mayor fabricante mundial de equipos para tecnología $5 \mathrm{G}$ en 
el mundo, suministre el equipo para red $5 \mathrm{G}$ en Brasil. Existe, dentro del gobierno, una lucha de brazos sobre el tema donde, por un lado, el llamado "núcleo ideológico del gobierno" que, como el presidente Bolsonaro, comparte la posición ideológica de derecha, el conservadurismo en las costumbres y el estilo de política populista y en línea del presidente Donald Trump; y, por otro lado, un grupo más pragmático, que incluye a la Ministra de Agricultura, Tereza Cristina, quien representa los intereses de la agricultura de exportación.

El presidente deberá decidir si acepta las demandas de Donald Trump, a quien Bolsonaro dedica una idolatría servil, hasta el punto de imitar sin crítica todas las actitudes locas del presidente estadounidense, o de servir a los intereses de una de sus principales bases de apoyo político, que son productores de soja y productores de carne, que tienen su principal mercado en China.

Según lo informado por WIZIACK y URIBE (2020):

El Ministro de Relaciones Exteriores, Ernesto Araújo, y el ministro de la Oficina de Seguridad Institucional (GSI) de la Presidencia de la República, el general Augusto Heleno, convencieron al presidente Jair Bolsonaro de que la subasta de $5 \mathrm{G}$ debería ofrecer restricciones a los fabricantes de equipos chinos como Huawei. Como resultado de esta presión, Bolsonaro dijo en una transmisión por Internet el jueves (11/6/2020) que el evento tendrá en cuenta "soberanía, seguridad de datos y política exterior". Es decir, la elección de nuevos estándares tecnológicos para telefonía ha dejado de ser técnica y ha adquirido una connotación geopolítica, debido a que, con esta condición, Brasil manifestará su apoyo a Estados Unidos, que está luchando una disputa de fuerzas políticas y económicas con China y requiere salvaguardas para los equipos de Huawei de los países aliados.

En el documento entregado por el Ministro de Relaciones Exteriores, Ernesto Araújo, que expresa la posición favorable de su ministerio para excluir a Huawei de la infraestructura de tecnología $5 \mathrm{G}$ en Brasil, el ministro sostiene que Brasil no sufriría ningún tipo de sanción comercial, porque China tiene como sus mayores proveedores de materias primas y alimentos a los Estados Unidos, Brasil y Australia. Para él, si los tres se unieran en apoyo de Donald Trump, los chinos no tendrían salida y continuarían importando de estos países (WIZIACK y URIBE, 2020).

La ministra de Agricultura, Tereza Cristina, no lo cree así. Para ella, cualquier tipo de restricción sobre China en el suministro de equipos de red $5 \mathrm{G}$ tendrá efectos nocivos en el rendimiento de los agronegocios, el único sector activo en este momento pandémico. Las personas que siguen las discusiones dicen que la ministra considera que las amenazas a China han cruzado la línea y, de hecho, está considerando abandonar el cargo si este enfrentamiento persiste.

Cabe señalar que la exclusión de Huawei de la implementación de $5 \mathrm{G}$ en Brasil, además de no tener sentido geopolítico, ya que Brasil no tiene nada que ganar, representará una pérdida concreta para el país, cuyo costo será asumido por todos en forma de tarifas más caras y demoras en la provisión de servicios. Esto se debe a que el equipo de Huawei, además de ser mejor y más barato, tiene la ventaja de "hablar" con todos los equipos de 
otros fabricantes, Nokia, Ericsson y Samsung, algo que el equipo de estos fabricantes no hace. Como parte de la red que actualmente funciona con tecnologías $3 G$ y $5 G$ que utilizan equipos Huawei, el uso exclusivo de los equipos de estos otros fabricantes en la red $5 \mathrm{G}$ obligaría a los operadores a cambiar todos los equipos Huawei actualmente utilizados en redes 2G, $3 G$ y $4 G$, lo que significaría un mayor costo, que finalmente recaerá en los usuarios, y un retraso mucho mayor antes de que esta nueva tecnología con gran potencial para revolucionar numerosos servicios y aumentar la productividad de las empresas esté disponible para personas, empresas y gobiernos.

Incluso con la presión estadounidense y el liderazgo chino en 5G, hasta ahora, el gobierno no ha emitido ninguna norma que restrinja las operaciones de Huawei en Brasil (WARTH, 2020). Hacerlo sin duda será un hito en las relaciones bilaterales entre los dos países.

\section{Relaciones comerciales Brasil-China (2000-2020)}

Si hay un campo en el que las relaciones chino-brasileñas son indudablemente exitosas, es el de las relaciones comerciales. Ni siquiera la turbulencia en las relaciones políticas bilaterales que hemos informado antes y, más recientemente, la pandemia de Covid-19, han afectado los flujos comerciales bilaterales.

China es ahora el principal destino de las exportaciones brasileñas y la principal fuente de bienes que el país compra en el extranjero. La inversión extranjera directa de China en Brasil ha aumentado significativamente en los últimos años. Actualmente hay más de 200 empresas chinas que operan en Brasil, en los sectores más diversos, como infraestructura, energía, finanzas, manufactura, agronegocios, tecnología de la información, transporte y logística, minería y acero y comercio. En la dirección opuesta, también hay casi una docena de empresas brasileñas con unidades industriales en China, algunas con más de 2 mil empleados, como WEG, además de varias oficinas de representación comercial, servicios legales y otros. La Asociación de Empresas Brasileñas en China tiene aproximadamente 60 miembros.

En las relaciones comerciales entre Brasil y China, a diferencia de otras áreas de cooperación, los agentes no gubernamentales son preponderantes, a pesar de la gran cantidad de empresas chinas que invierten en Brasil son de propiedad estatal. Aunque puede haber incentivos gubernamentales para llevar a cabo estos negocios (especialmente la inversión extranjera directa), las decisiones a nivel de las empresas involucradas se toman en función del cálculo económico, es decir, la búsqueda de parte de las ventajas económicas que pueden estar relacionadas con la búsqueda de nuevos mercados, reducción de costos de producción, garantía de acceso a fuentes de energía y materias primas y adquisición de activos estratégicos. 


\section{Comercio bilateral Brasil-China}

Como se ve en el e Gráfico 1 y en el Cuadro 1, el flujo comercial entre Brasil y China aumentó de US \$2,3 mil millones en 2000 a US \$98,6 mil millones en 2019.

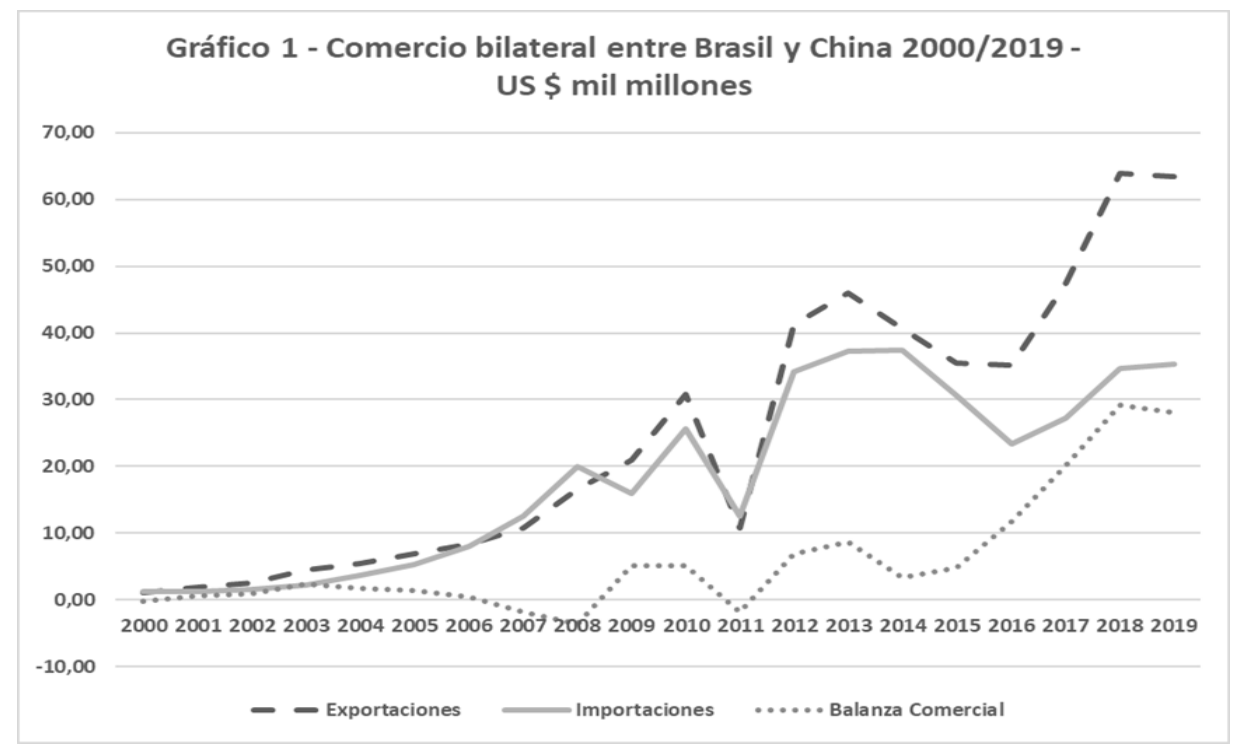

Cuadro 1 - comercio bilateral entre Brasil y China - 2000/2019 miles de millones de \$ EE.UU - Fonte: Ministério da Industria, Comércio Exterior y Serviçios

\begin{tabular}{lcccc} 
Año & Exportaciones & Importaciones & Comercio Bilateral & Balanza Comercial \\
2000 & 1,085 & 1,219 & 2,304 & $-0,134$ \\
\hline 2001 & 1,901 & 1,320 & 3,221 & 0,581 \\
\hline 2002 & 2,517 & 1,549 & 4,066 & 0,968 \\
\hline 2003 & 4,531 & 2,143 & 6,674 & 2,388 \\
\hline 2004 & 5,439 & 3,703 & 9,142 & 1,735 \\
\hline 2005 & 6,827 & 5,337 & 12,164 & 1,490 \\
\hline 2006 & 8,398 & 7,975 & 16,374 & 0,423 \\
\hline 2007 & 10,777 & 12,596 & 23,373 & $-1,820$ \\
\hline 2008 & 16,520 & 20,038 & 36,558 & $-3,518$ \\
\hline 2009 & 20,995 & 15,905 & 36,899 & 5,090 \\
\hline 2010 & 30,748 & 25,971 & 56,339 & 5,156 \\
\hline 2011 & 10,777 & 12,596 & 23,373 & $-1,820$ \\
\hline 2012 & 41,226 & 75,471 & 6,981 \\
\hline 2013 & 46,023 & 34,245 & 83,349 & 8,697 \\
\hline 2014 & 40,612 & 77,951 & 3,273 \\
\hline 2015 & 35,550 & 66,264 & 4,835 \\
\hline 2016 & 35,133 & 58,491 & 11,776 \\
\hline 2017 & 47,488 & 74,810 & 20,167 \\
\hline 2018 & 63,930 & 98,660 & 29,200 \\
\hline 2019 & 63,358 & 98,628 & 28,087 \\
\hline
\end{tabular}


Cuadro 2 - Exportaciones de Brasil - China / Estados Unidos (miles de millones de \$ EE.UU.)

\begin{tabular}{lrr}
\hline Año & China & \multicolumn{2}{c}{ Estados Unidos } \\
\hline 2000 & 1,085 & 13,161 \\
2001 & 1,901 & 14,149 \\
2002 & 2,517 & 15,334 \\
2003 & 4,531 & 16,678 \\
2004 & 5,439 & 20,003 \\
2005 & 6,827 & 22,645 \\
2006 & 8,398 & 24,508 \\
2007 & 10,777 & 25,054 \\
2008 & 16,520 & 27,411 \\
2009 & 20,995 & 15,599 \\
2010 & 30,748 & 19,301 \\
2011 & 44,305 & 25,797 \\
2012 & 41,226 & 26,646 \\
2013 & 46,023 & 24,646 \\
2014 & 40,612 & 27,024 \\
2015 & 35,550 & 24,059 \\
2016 & 35,133 & 23,156 \\
2017 & 47,488 & 26,873 \\
2018 & 63,930 & 28,697 \\
2019 & 63,358 & 29,716 \\
\hline
\end{tabular}

Fuente: Ministerio de Industria, Comercio Exterior y Servicios.
Durante estos 20 años, Brasil ha tenido superávit comercial con China en 16 años y déficit en solo cuatro: 2000, 2007, 2008 y 2011.

Como también se puede ver en el Cuadro 2 y el Gráfico 2, en 2009, China superó a los Estados Unidos como el principal destino de las exportaciones brasileñas. También se observa que, entre 2018 y 2019, aunque las exportaciones a los Estados Unidos y China mostraron una tendencia al alza, las exportaciones a China alcanzaron más del doble de las exportaciones a los Estados Unidos. Como ya hemos señalado, el flujo comercial entre los dos países mostró un valor récord de casi US $\$ 100 \mathrm{mil}$ millones. Este aumento significativo de las exportaciones brasileñas a China en estos dos años fue, en parte, el resultado de la desviación comercial causada por la guerra comercial entre Estados Unidos y China.

\section{Gráfico 2 - Exportaciones de Brasil - China / Estados Unidos (miles de millones de \$ EE.UU.)}

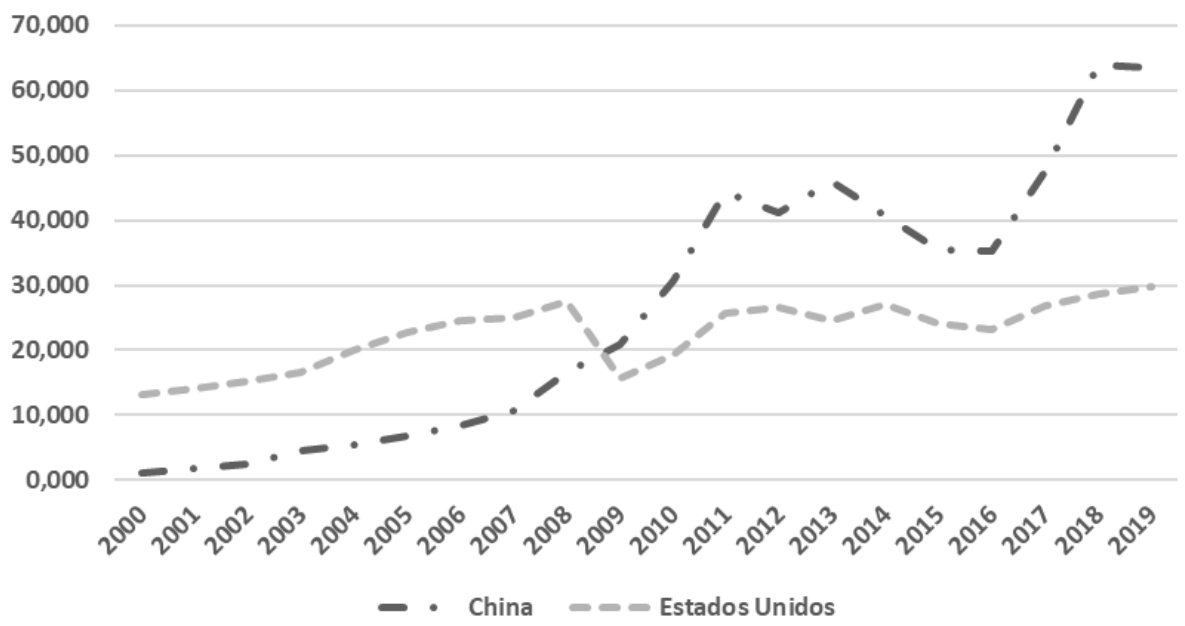


Otro hecho que merece destacarse es la disparidad en la composición sectorial del comercio bilateral entre los dos países. Como se muestra en las Figuras 1 y 2 , mientras que las exportaciones brasileñas a China son básicamente productos básicos minerales y agrícolas de bajo valor agregado, las importaciones brasileñas de China son productos manufacturados con alto valor agregado. En 2018, solo tres productos -soja, petróleo, mineral de hierro- sumaron el $82 \%$ de las exportaciones brasileñas a China (Figura 1). En el sentido opuesto, las importaciones brasileñas de China son casi $100 \%$ de productos manufacturados, sobre todo productos electrónicos, productos químicos, máquinas y equipos (Figura 2).

\section{Figura 1 - Descripción general de los productos exportados por Brasil a China en 2018}

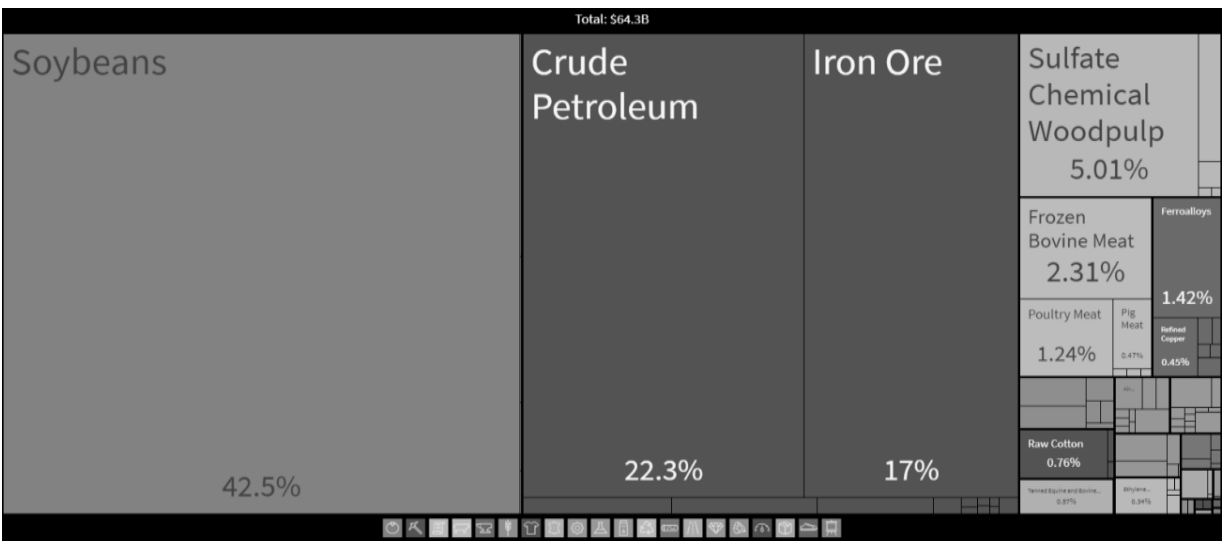

Figura 2: Descripción general de los productos importados por Brasil de China en 2018

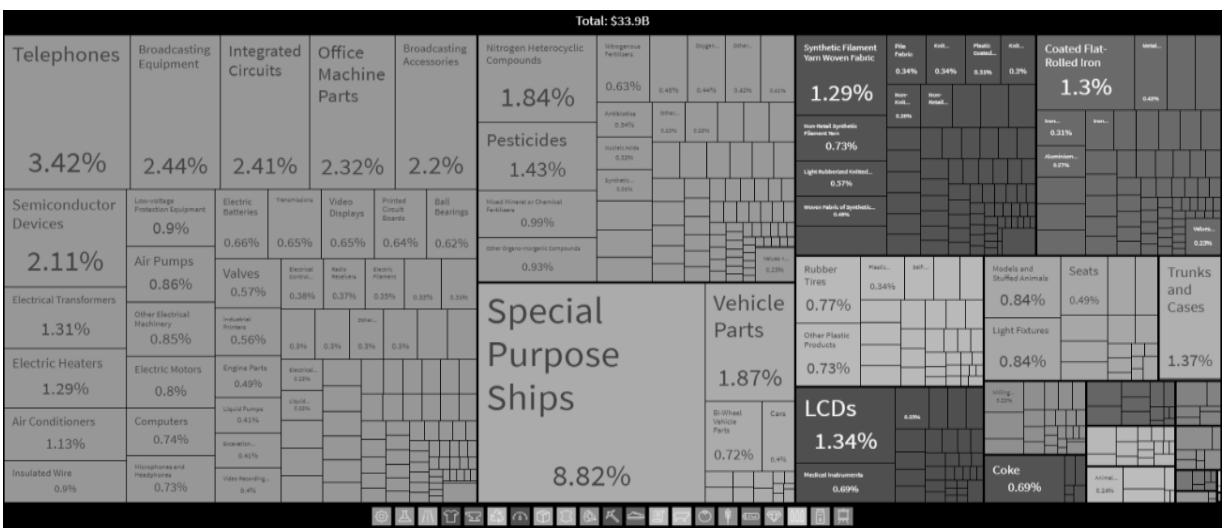

Fuente: OEC - Observatory of Economic Complexity (https://oec.world/)

Esta asimetría ha generado preocupaciones y, sobre todo, quejas de algunos sectores, principalmente de la industria manufacturera brasileña. Brasil sigue siendo un importante 
productor mundial de bienes manufacturados y bienes de capital. Resulta que esta nueva división internacional del trabajo, que se estableció después de la aparición de China como "la fábrica del mundo" y, sobre todo, por la fuerte demanda de productos minerales y agrícolas, ha contribuido, en opinión de algunos, a que Brasil retroceda en su estructura industrial y dé lugar al fenómeno que algunos estudiosos sobre el tema clasifican como "desindustrialización prematura de la economía brasileña" y otros, como "reprimarización de la economía brasileña", que es lo mismo.

Esta gran dependencia de China en el suministro de maquinaria, equipos e insumos industriales se evidenció en la pandemia del Covid-19, cuando las industrias de todo el mundo tuvieron su producción comprometida debido a la falta de insumos importados de China. En Brasil, Abinee (Asociación Brasileña de la Industria Eléctrica y Electrónica) afirma que el $57 \%$ de las empresas asociadas tuvieron problemas para recibir materiales, componentes e insumos de China, debido al brote del coronavirus en el país asiático (NARCISO, 2020).

\section{Evolución de la inversión directa de China en Brasil en el período 2010- 2019}

Dependiendo de la fuente consultada, la información sobre las inversiones chinas en Brasil varía ampliamente. Esto se debe a las diferentes metodologías utilizadas para capturar la información. Las dos principales fuentes oficiales sobre la inversión directa de China en Brasil son el Banco Central de Brasil y la Oficina Nacional de Estadísticas de China. Sin embargo, estas dos fuentes presentan el mismo problema: el Banco Central de Brasil registra el último país del que se originó la inversión y la Oficina Nacional de Estadísticas de China registra el primer país al que se dirigió la inversión. Resulta que muchas empresas usan participaciones ubicadas en terceros países, generalmente paraísos fiscales, para negociar sus inversiones en el extranjero. Por lo tanto, algunas inversiones realizadas en Brasil por compañías chinas aparecen en las estadísticas del Banco Central de Brasil como originadas en las Islas Caimán u otros países. Del mismo modo, las inversiones dirigidas a Brasil aparecen en las estadísticas de la Oficina Nacional de Estadísticas de China como si hubieran ido a estos mismos paraísos fiscales.

La solución para sortear estas dificultades ha sido recurrir a fuentes no oficiales, que también tienen problemas, ya que generalmente se basan en anuncios de inversión publicados en los principales medios de comunicación del país. Aunque las más grandes inversiones terminan siendo capturadas de esta manera, otras inversiones, generalmente de menor valor, terminan sin ser consideradas.

El China Global Investment Tracker (CGIT), publicado por el American Enterprise Institute y la Fundación Heritage, es una fuente ampliamente utilizada, pero solo calcula inversiones que superan los 100 millones de dólares. En Brasil, la fuente más confiable es el Consejo Empresarial Brasil-China (CEBC), que rastrea los anuncios de inversión y publica un informe anual sobre las inversiones de China en Brasil. Además de recopilar anuncios de inversión publicados en la prensa, CEBC confirma las cifras con las empresas y también captura información directamente de las empresas chinas que operan en Brasil. 
En un trabajo reciente, investigadores de la Universidad Federal de Río de Janeiro crearon una base de datos llamada Base GIC-IE / UFRJ, reunieron información de varias fuentes y publicaron un extenso estudio que analiza las inversiones chinas en Brasil en el período 2010-2016. En el cuadro 3 y el gráfico 3, es posible observar la información producida por cada una de estas instituciones para el período 2005-2019.

Cuadro 3 Inversiones chinas en Brasil 2005-2019 (en miles de millones de \$ EE.UU.)

\begin{tabular}{|c|c|c|c|c|}
\hline $\begin{array}{c}\text { Fonte/A } \\
\text { no }\end{array}$ & CGIT & CEBC & PwC & GIC \\
\hline 2005 & 0,67 & & & \\
\hline 2006 & 1,63 & & & \\
\hline 2007 & 0,00 & & & \\
\hline 2008 & 0,00 & 0,50 & & \\
\hline 2009 & 1,00 & & & \\
\hline 2010 & 13,49 & 13,10 & 13,70 & 13,30 \\
\hline 2011 & 8,25 & 8,00 & 8,30 & 6,90 \\
\hline 2012 & 2,60 & 3,40 & 0,50 & 2,50 \\
\hline 2013 & 3,02 & 3,40 & 3,70 & 3,10 \\
\hline 2014 & 3,37 & 1,70 & 2,80 & 1,80 \\
\hline 2015 & 5,52 & 7,40 & 4,80 & 7,60 \\
\hline 2016 & 14,08 & 8,40 & 5,10 & 8,70 \\
\hline 2017 & 8,62 & 8,80 & 13,00 & \\
\hline 2018 & 1,79 & 3,00 & 0,20 & \\
\hline 2019 & 4,61 & & 1,90 & \\
\hline
\end{tabular}

Elaboración propia

CGIT - China Global Investment Tracker

CEBC - Conselho Empresarial Brasil-China

PwC - PricewaterhouseCoopers

GIC - Base GIC-IE/ UFRJ

n.d.- no disponible 


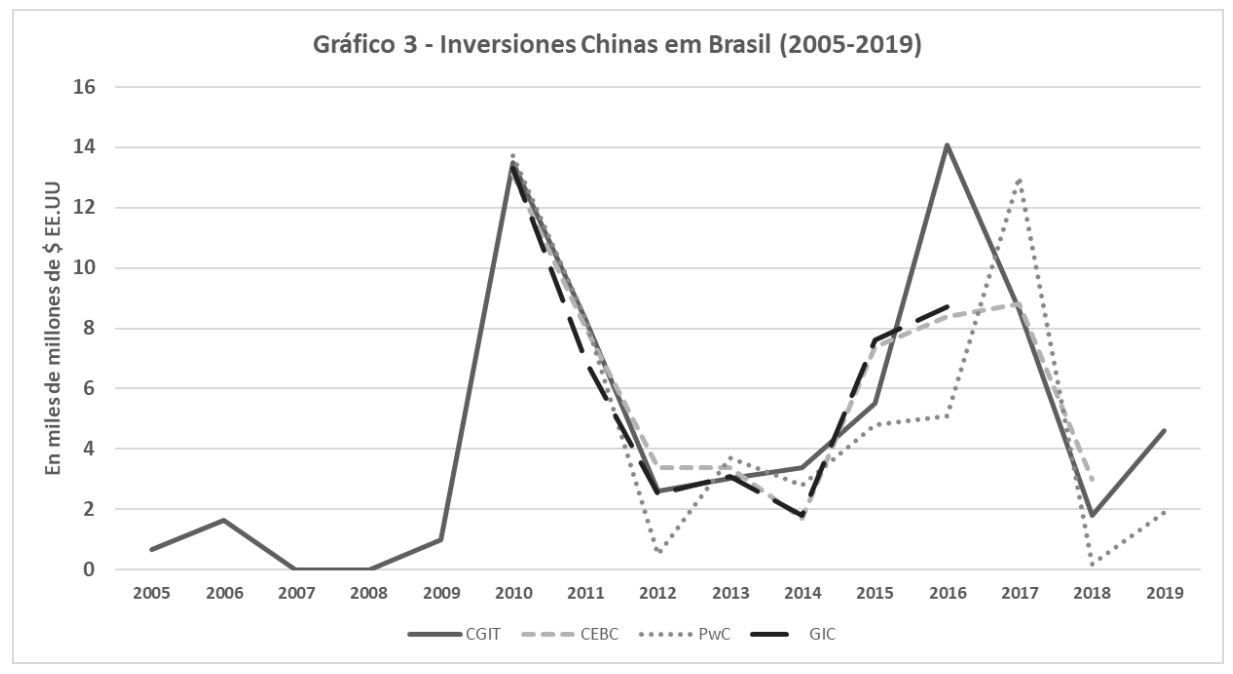

A pesar de las diferencias entre cada una de las fuentes, es posible observar en el Gráfico 3 el mismo patrón de comportamiento de la inversión china en Brasil durante los últimos 15 años. En el período 2005-2010, las inversiones chinas en Brasil eran casi inexistentes. Entre 2010 y 2011, mostraron un fuerte aumento y alcanzaron en 2010 alrededor de US \$13,5 mil millones. Entre 2012 y 2014 las inversiones cayeron bruscamente y entre 2015 y 2017 comenzaron a crecer nuevamente. En 2018 nuevamente hay una fuerte caída y un comienzo de recuperación en 2019.

Los dos períodos de disminución de la inversión directa china en Brasil (2012, 2014 y 2018) se produjeron por diferentes razones. El período 2012-2014 coincide con el momento en que los efectos de la crisis financiera de 2008 se sienten con mayor intensidad en Europa y los países en desarrollo. Hay una fuerte desaceleración en la economía mundial y una caída generalizada en el precio de los productos básicos. China, que había estado creciendo a tasas de alrededor del $9 \%$ por año, redujo su crecimiento al 7,8\%, en 2012, debido al cambio en su modelo de desarrollo que comenzó a favorecer el consumo interno. En el mismo año, la economía brasileña creció solo un $0,9 \%$, lo que dio comienzo a un período de crisis económica y política que terminaría con la destitución de la presidenta Dilma Rousseff, en 2016.

La caída del 66\% en las inversiones chinas en Brasil, entre 2017 y 2018, se produjo principalmente debido a las elecciones para presidente de la República en 2018. Dada la incertidumbre del marco político y la expectativa de cambios importantes en la política económica en Brasil, las inversiones extranjeras mostraron un fuerte reflujo. Las nuevas medidas de control del gobierno chino sobre las llamadas "inversiones irracionales" y la reducción de la liquidez en el sistema financiero en China también deben haber contribuido a esto. De hecho, las inversiones chinas, en 2018, disminuyeron no solo en Brasil, sino en todo el mundo. En 2019, nuevamente mostraron una tendencia de crecimiento en Brasil.

Es importante tener en cuenta que, además de la incertidumbre relacionada con las elecciones de 2018, el período 2018-2019 estuvo marcado por una serie de incidentes que 
arrojaron dudas sobre la evolución de las relaciones entre Brasil y China al comienzo del nuevo gobierno, como ya hemos analizado.

\section{Principales características de las inversiones chinas en Brasil.}

Muchos analistas tienden a dividir las inversiones chinas en Brasil en fases. Según Cariello (2019), el flujo de inversiones chinas en Brasil se puede dividir en cuatro fases. En la primera fase, que se extiende hasta 2010, las inversiones chinas se concentraron en el área de los productos básicos, para satisfacer, sobre todo, la alta demanda china de petróleo, mineral de hierro y soja. La segunda fase se extiende desde 2010 hasta mediados de 2013. Durante este período, las principales inversiones se dirigieron al área industrial, centrándose en la búsqueda del mercado de consumo brasileño. La tercera fase, según el autor, que comenzó en 2013, está marcada por las inversiones en el área de servicios, con énfasis en el desempeño de los bancos chinos. Finalmente, la última fase, que comienza en 2014, se destaca por la afluencia de inversiones masivas en las áreas de electricidad e infraestructura. "Además, en esta última fase, también se verificaron importantes inversiones en áreas con gran potencial, como en los sectores de petróleo y gas, agronegocios y, más recientemente, tecnología" (Cariello, 2019, p. 9).

Con respecto a la forma en que las inversiones chinas ingresan a Brasil, Cariello distingue tres etapas: en una primera fase, que se extiende de 2007 a 2011, China buscó proyectos llamados "greenfield", el nombre dado a un proyecto que comienza desde cero, como construir una fábrica. De 2012 a 2016, la preferencia se desplazó a la compra de control o participación minoritaria en compañías ya establecidas, llamadas inversiones "brownfield". Finalmente, a partir de 2017, las inversiones se centraron más en los programas de concesiones y privatizaciones (WIZIACK, 2019).

Ya Para Sheng (2019), es posible dividir las inversiones chinas en Brasil en tres fases diferentes. En la primera, que se extiende de 2002 a 2010, las inversiones chinas se concentraron en actividades relacionadas con los productos básicos, mientras que la segunda fase, que se extiende de 2011 a 2013, aprovecha el buen momento económico y el potencial del mercado de consumo interno en Brasil. Los chinos se concentraron en el sector manufacturero, especialmente en maquinaria, equipos, automotores y electrónicos. La tercera fase, según el autor, comienza en 2013 y se extiende hasta la actualidad, caracterizada por la contribución de capital en el área de servicios.

Las dos periodizaciones coinciden más o menos al indicar que las inversiones chinas en Brasil desde principios del siglo XXI han seguido la secuencia productos básicos-manufacturas-servicios, con la última etapa, la de las inversiones en el sector de servicios, dividiéndose en servicios al consumidor, como el transporte urbano y el comercio electrónico, servicios a empresas, sobre todo, bancos, y servicios industriales de utilidad pública, principalmente producción, generación y distribución de energía eléctrica.

El Cuadro 4 enumera las principales inversiones directas realizadas por China en Brasil en el período 2009-2019 e indica el año de la inversión, la empresa, el valor de la inversión y el sector y subsector en el que opera la empresa. En este período de diez años, la inversión directa total de China en Brasil alcanzó los US \$60.360 millones. 
Esta cifra probablemente se subestima, ya que solo se incluyen inversiones de más de US \$100 millones, de acuerdo con la metodología del China Global Investment Tracker publicado por el American Enterprise Institute y la Fundación Heritage. Como ya hemos señalado, no existe una fuente de información totalmente confiable, pero, en general, los grandes números capturados por las diferentes fuentes (ver cuadro 3 y gráfico 3 ) tienden a presentar tendencias y valores muy similares. Optamos por la base de datos CGTI, porque era la única que cubría todos los años, de 2009 a 2019.

En cualquier caso, es importante destacar que, sobre la base de CGTI, como se muestra en el cuadro 4, solo hay 39 empresas, cuando sabemos, según lo verificado por otras fuentes, que hay un número mucho mayor de empresas chinas que operan en Brasil. En el Directorio de Miembros de la Asociación Brasileña de Empresas Chinas de 2019, hay 116 empresas chinas que operan en el país. El embajador chino en Brasil declaró en una entrevista el 21/10/2019 que "hoy, más de 300 empresas chinas invierten en Brasil, 25 de las cuales se encuentran entre las 500 más grandes del mundo" (MOTTA, 2019). Si bien muchas de estas empresas realizan inversiones de menor valor, por debajo de los US \$100 millones, todas operan en sectores importantes, como manufactura, tecnología de la información, transporte y logística, entre otros.

\begin{tabular}{|c|c|c|}
\hline \multicolumn{3}{|c|}{ Cuadro 4 - Inversiones chinas en Brasil 2009-2019 (más de US \$ 100 millones) } \\
\hline Empresa inversora & $\begin{array}{l}\text { Valor en } \\
\text { millones de Sector } \\
\text { dólares }\end{array}$ & Subsector \\
\hline 2019 CNPC, CNOOC & 1.900 Energía & Petróleo \\
\hline 2019 State Grid (1) & 1.030 Energía & Energía alternativa \\
\hline 2019 China General Nuclear & 780 Energía & Energía alternativa \\
\hline 2019 China Communications Construction & 220 Metales & Minería \\
\hline 2018 Didi Chuxing & 600 Transporte & Transporte urbano \\
\hline 2018 Three Gorges & 190 Energía & Generación de energía \\
\hline 2018 China Energy Engineering & 190 Utilidades & Saneamiento \\
\hline 2018 Tencent & 180 Finanzas & Finanzas \\
\hline 2018 Alibaba & 100 Finanzas & Finanzas \\
\hline 2017 State Grid & 3.440 Energía & Distribución de energía \\
\hline 2017 State Power Investment & 2.260 Energía & Generación de energía \\
\hline 2017 CITIC-led fund & 1.100 Agricultura & Agricultura \\
\hline 2017 China Merchants & 920 Transporte & Navegación \\
\hline 2017 China Communications Construction & 280 Tranporte & Navegación \\
\hline 2017 Shanghai Pengxin & 250 Agricultura & Agricultura \\
\hline 2017 CNPC & 120 Energía & Petróleo \\
\hline 2017 China Communications Construction & 100 Construción & Construcción \\
\hline 2016 State Grid & 4.910 Energía & Distribución de energía \\
\hline 2016 Three Gorges & 3.660 Energía & Generación de energía \\
\hline 2016 China Molybdenum & 1.500 Química & Metales no ferrosos \\
\hline 2016 Three Gorges, China Development Bank & 1.200 Energía & Generación de energía \\
\hline $2016 \mathrm{CIC}$ & 1.090 Energía & Refinación de petróleo \\
\hline $2016 \mathrm{CIC}$ & 410 Energía & Refinación de petróleo \\
\hline 2016 Shanghai Pengxin & 290 Agricultura & Agricultura \\
\hline 2016 State Grid & 110 Energía & Distribución de energía \\
\hline 2016 Xuzhou Construction Machinery & 100 Construcción & Construcción \\
\hline 2016 Didi Chuxing & 100 Transporte & Tranporte urbano \\
\hline
\end{tabular}




\begin{tabular}{|c|c|c|}
\hline 2015 ICBC & 2.000 Energía & Petróleo \\
\hline 2015 Three Gorges & 490 Energía & Generación de energía \\
\hline 2015 HNA & 460 Transporte & Aviación \\
\hline 2015 China Communications Bank & 170 Finanzas & Finanzas \\
\hline 2015 BYD & 100 Energía & Energía alternativa \\
\hline 2014 COFCO, Hopu Investment & 750 Agricultura & Agricultura \\
\hline 2014 China Construction Bank & 720 Finanzas & Finanzas \\
\hline 2014 Three Gorges & 390 Energía & Generación de energía \\
\hline 2014 Sany Heavy & 300 Construcción & Construcción \\
\hline 2014 Three Gorges & 140 Energía & Generación de energía \\
\hline 2014 ZTE & 100 Tecnología & Tecnología \\
\hline 2013 CNPC, CNOOC & 1.400 Energía & Petróleo \\
\hline 2013 China Construction Bank & 720 Finanzas & Finanzas \\
\hline 2013 COFCO & 320 Agricultura & Agricultura \\
\hline 2013 Three Gorges & 250 Energía & Generación de energía \\
\hline 2013 Xugong Construction Machinery & 200 Construcción & Construcción \\
\hline 2013 Three Gorges & 130 Energía & Generación de energía \\
\hline 2012 State Grid & 940 Energía & Distribución de energía \\
\hline 2012 CIC & 460 Logística & Logística \\
\hline 2012 Beijing Auto & 300 Tranporte & Automotor \\
\hline 2012 China Construction Bank & 200 Finanzas & Finanzas \\
\hline 2012 Lenovo & 150 Tecnología & Tecnología \\
\hline 2011 Sinopec & 4.800 Energía & Petróleo \\
\hline 2011 Taiyuan Iron, CITIC, Baosteel & 1.950 Metales & Metalurgia \\
\hline 2011 Chongqing Grain & 570 Agricultura & Agricultura \\
\hline 2011 Chery Auto & 530 Transporte & Automotor \\
\hline 2011 ZTE & 200 Tecnología & Tecnología \\
\hline 2011 ICBC & 100 Finanzas & Finanzas \\
\hline 2011 JAC Motors & 100 Transporte & Automotiva \\
\hline 2010 Sinopec & 7.100 Energía & Petróleo \\
\hline 2010 Sinochem & 3.070 Energía & Petroléo \\
\hline 2010 State Grid & 1.720 Energía & Distribución de energía \\
\hline 2010 East China Mineral Exploration and Development Bureau (Jiangsu) & 1.200 Metales & Minería \\
\hline $2010 \mathrm{CIC}$ & 200 Finanzas & Finanzas \\
\hline 2010 Sany Heavy & 200 Construcción & Construcción \\
\hline $2009 \mathrm{ClC}$ & 500 Metales & Minería \\
\hline 2009 Wuhan Iron and Steel & 400 Metales & Minería \\
\hline TOTAL & 60.360 & \\
\hline
\end{tabular}

Fuente: China Global Investment Tracker (GCIT)

(1) Aunque en la base de datos de GCIT hay China General Nuclear, al revisar los datos se encontró que es State Grid

\section{Cuadro 5 - Cinco principales empresas inversoras en Brasil en el período 2009-2019}

\begin{tabular}{|l|r|l|}
\hline Empresa Inversora & $\begin{array}{c}\text { Valor } \\
\text { (millones de } \\
\text { EE.UU.) }\end{array}$ & Sector \\
\hline State Grid & 12.150 & Energía \\
\hline Sinopec & 11.900 & Petróleo \\
\hline Three Gorges & 6.450 & Energía \\
\hline CNPC, CNOOC & 3.420 & Petróleo \\
\hline Sinochem & 3.070 & Petróleo \\
\hline Total & $\mathbf{3 6 . 9 9 0}$ & \\
\hline
\end{tabular}

Fuente: CGIT
Una característica importante de las inversiones chinas en Brasil es que algunas pocas empresas concentran la mayor parte del monto total invertido. Como se muestra en Cuadro 5, solo cinco compañías, todas en el sector petrolero y energético, invirtieron, entre 2009 y 2019, un total de US $\$ 36,99$ mil millones en Brasil, lo que corresponde al $61,3 \%$ del total invertido en el período. Esta concentración también se observa en relación con los 


\section{Cuadro 6 - Distribución de las inversiones chinas en Brasil por sector de actividad en el período 2009-2019 (1)}

Valor

Sector (millones Participación \% de \$EE.UU.)

\begin{tabular}{lrr}
\hline Energía & 21.740 & $36,02 \%$ \\
Petróleo & 18.390 & $30,47 \%$ \\
Finanzas & 6.850 & $11,35 \%$ \\
Metales & 5.050 & $8,37 \%$ \\
Agricultura & 3.280 & $5,43 \%$ \\
Transporte & 2.080 & $3,45 \%$ \\
Automotor & 930 & $1,54 \%$ \\
Equipos & 800 & $1,33 \%$ \\
Construcción & 600 & $0,99 \%$ \\
Tecnología & 450 & $0,75 \%$ \\
Saneamento & 190 & $0,31 \%$ \\
\hline Total & 60.360 & $100,00 \%$ \\
\hline
\end{tabular}

(1) Inversiones superiores a US $\$ 100$ millone Fuente: CGIT

\section{Cuadro 7 - Número de empresas} chinas que operan en Brasil por sector de actividad (2019)

\begin{tabular}{lc}
\hline \multicolumn{1}{c}{ Setor de atividade } & $\begin{array}{c}\text { Número } \\
\text { de } \\
\text { Empresas }\end{array}$ \\
\hline Manufactura & 34 \\
Energía & 23 \\
Comercio e Inversiones & 20 \\
Infraestructura & 19 \\
Transporte y Logística & 13 \\
Finanzas & 11 \\
Tecnología de Informacion & 11 \\
Agronegocios & 7 \\
Minería y acero & 4 \\
Telecomunicaciones & 2 \\
\hline
\end{tabular}

Fuente: Associação Brasileira de Empresas Chinesas (ABEC) sectores a los que se dirigieron las inversiones directas chinas en el período. Como se muestra en cuadro 6 , solo dos sectores, energía y petróleo, concentran el $66 \%$ de las inversiones totales realizadas entre 2009 y 2019.

Este alto grado de concentración de la inversión directa china en Brasil en el sector energético y petrolero se deriva de dos hechos: las inversiones en el sector petrolero están relacionadas con el hecho de que China consume 13,5 millones de barriles/día, lo que corresponde al 13,5\% del consumo mundial y produce solo 3.978 barriles/día, lo que representa el $4 \%$ de la producción mundial de petróleo (ANP, 2019). Las inversiones en el sector energético, especialmente en el área de distribución, están relacionadas con el hecho de que Brasil tiene características muy similares a las de China con respecto a la generación y distribución de energía hidroeléctrica, o sea, la producción en algunas áreas remotas del país y la necesidad de transportar energía a largas distancias a los principales centros de consumo. Gracias a la experiencia adquirida por las empresas chinas en esta área y al hecho de que el gobierno brasileño está privatizando sus empresas estatales en el sector, el área de generación y distribución de electricidad ha sido uno de los atractivos para las inversiones de las empresas chinas en Brasil.

Cabe señalar, sin embargo, que se están realizando muchas inversiones más pequeñas en otros sectores de actividad. Como se puede ver en el Cuadro 7, organizado desde el Directorio de Miembros de la Asociación Brasileña de Empresas Chinas $(A B E C)$, solo en el sector manufacturero hay 34 empresas chinas que operan en Brasil. La misma tabla muestra que hay $23 \mathrm{em}-$ presas en el sector energético, 20 empresas que operan en comercio e inversión, 19 
empresas en el área de infraestructura, 13 en transporte y logística, 11 en el sector financiero, 11 en tecnología de la información, 7 en la agroindustria, 4 en el área siderúrgica y minera y 2 en telecomunicaciones. Según Yang Wanming, embajador de China en Brasil, "hoy el stock de inversión china en Brasil es de alrededor de US \$80 mil millones, siendo China una de las principales fuentes de inversión extranjera en el país" (MOTTA, 2020).

\section{Conclusión}

A pesar de la fuerte preferencia ideológica del presidente Jair Bolsonaro y su canciller, Ernesto Araújo, por el presidente Trump y la extrema derecha estadounidense, el gobierno brasileño, o al menos parte de él, es consciente de que China es, desde el punto de vista económico, más importante para Brasil que los Estados Unidos. Brasil no puede prescindir de China, ya sea como mercado de exportación, como proveedor de insumos esenciales para la industria brasileña, o como fuente de capital, tecnología e inversiones para sostener el crecimiento de la economía nacional.

El gobierno chino, por otro lado, como dice el exembajador brasileño en China, Marcos Caramuru, "ve a Brasil como un socio comercial importante que exporta bienes esenciales, con los cuales China debe tener buenas relaciones. Hoy vendemos aproximadamente el $70 \%$ de todo lo que China importa de la soja, un producto esencial para producir alimentos para animales; alrededor del $20 \%$ de mineral de hierro; y el $11 \%$ de todo el petróleo que importa China" (LUPION, 2019).

Esto lleva al presidente Bolsonaro y su canciller a jugar una especie de doble juego, mientras intenta complacer al presidente estadounidense y preservar las relaciones económicas bilaterales entre Brasil y China. En la reunión con el Ministro de Relaciones Exteriores de China, Wang Yi, en la tercera reunión del Diálogo Estratégico Global Brasil-China, celebrada en Brasilia, el 26/07/2019, el canciller brasileño, Ernesto Araújo, declaró que "tenemos la expectativa de que contaremos con gran presencia de China en los proyectos de infraestructura que estamos licitando en Brasil, no solo a través de inversiones bilaterales, sino también para los proyectos que serán financiados por el Nuevo Banco de Desarrollo de los BRICS " (AGÊNCIA EFE, 2019).

Aparentemente, el gobierno chino acoge con beneplácito algunas medidas económicas que ha tomado el actual gobierno brasileño, especialmente las reformas económicas y la reanudación de los programas de privatización y concesión a partir de 2020, lo que abre buenas oportunidades de inversión para las empresas chinas, especialmente en el área de construcción civil. En una entrevista reciente, el embajador de China en Brasil, Yang Wanming, declaró: " El gobierno brasileño se centra en reformas fiscales y de seguridad social y, con esto, las empresas chinas ven favorablemente el ambiente de inversión en Brasil. A la larga, la inversión china tendrá la oportunidad de crecer aún más” (MOTTA, 2020).

La principal conclusión a la que llegamos es que, a pesar de los cambios políticos que tuvieron lugar en Brasil en 2018 y de los riesgos asociados con la reorientación de la política exterior brasileña hacia una alineación incondicional con los Estados Unidos, el comercio bilateral y la inversión directa de China en el país se mantienen estables, guiados por una perspectiva a largo plazo impulsada por tres vectores: la gran disponibilidad de recursos 
naturales, el tamaño del mercado de consumo brasileño y los proyectos de concesión y privatización de servicios públicos actualmente en curso en Brasil. Sin embargo, si el gobierno brasileño continúa, irresponsablemente, atacando a China solo para jugar el juego de los Estados Unidos, será inevitable que el entorno político eventualmente contamine el entorno económico. La decisión del gobierno brasileño de excluir o no a la empresa china Huawei de la construcción de infraestructura para la tecnología 5G será decisiva para definir el futuro de las relaciones bilaterales entre Brasil y China.

\section{Referencias bibliográficas}

AGÊNCIA BRASIL. (25 de octubre de 2020). Bolsonaro se encontra com o presidente chinês para a assinatura de acordos. Agência Brasil. https://agenciabrasil.ebc.com.br/politica/noticia/2019-10/bolsonaro-se-encontra-com-presidente-chines-para-assinatura-de-acordos

AGÊNCIA EFE. (26 de julio de 2019) China quer investir em infraestrutura no Brasil e comprar mais alimentos. UOL. https://noticias.uol.com.br/ultimas-noticias/efe/2019/07/26/china-quer-investir-em-infraestrutura-no-brasil-e-comprar-mais-alimentos.htm.

ANP - Agência Nacional do Petróleo Gás Natural e Biocombustíveis. (31 de marzo de 2020). Anuário Estatístico Brasileiro de Petróleo, Gás Natural e Biocombustíveis. http://www.anp.gov.br/arquivos/central-conteudos/anuario-estatistico/2019/2019-anuario-versao-impressao.pdf

BARBOSA, R. (17 de julio de 2020). Parceria Estratégica Global com a China. O Estado de S. Paulo. https://opiniao.estadao.com.br/noticias/geral,parceria-estrategica-global-com-a-china-imp-,949512

BECARD, D. S. R. (2011). O que esperar das relações Brasil-China? Revista de Sociologia e Política, V. 19, № suplementar, 31-44. https://revistas.ufpr.br/rsp

BITENCOURT, R. e MURAKAWA, F. (20 de marzo de 2020). Bolsonaro fala em "página virada" e que problema com a China "não existe". Valor Econômico. https://valor.globo.com/politica/noticia/2020/03/20/bolsonaro-fala-em-pagina-viradae-que-problema-com-a-china-nao-existe.ghtml Acesso em 13/7/2020

DUARTE, L. (7 de julio de 2018). Como a guerra comercial entre EUA e China pode afetar o Brasil. BBC Brasil. https://www.bbc.com/portuguese/brasil-44745494

JANK, M. S., GUO, P., MIRANDA, S.H.G. (29 de mayo de 2020). Parceria Brasil-China para a segurança alimentar. O Estado de S. Paulo. https://opiniao.estadao.com.br/noticias/espaco-aberto, parceria-brasil-china-para-a-seguranca-alimentar,70003318194

JIANG, Z. Selected Works of Jiang Zemin. Volume 3. Pequim: Foreign Languages Press, 2010.

JORNAL NACIONAL (19 de marzo de 2020). Eduardo Bolsonaro culpa China por coronavírus e gera crise diplomática. G1. https://g1.globo.com/jornal-nacional/noticia/2020/03/19/eduardo-bolsonaro-culpa-china-por-coronavirus-e-gera- 
crise-diplomatica.ghtml

MACLEOD, M. J. (1999). Aspectos da Economia Interna da América Espanhola Colonial: Mãode-Obra; Tributação; Distribuição e Troca Behtell, L. (Ed.) História da América Latina. Volume II. América Latina Colonial. (pp. 188-269). Edusp.

MAGALHÃES, G. (5 de noviembre de 2020). Aceno de Bolsonaro a Taiwan desanima Pequim, diz alto funcionário do regime chinês. Folha de S. Paulo.

https://www1.folha.uol.com.br/mundo/2018/11/aceno-de-bolsonaro-a-taiwan-desanima-pequim-diz-alto-funcionario-do-regime-chines.shtml.

MENDES, L. H. e ZAIA, C. (10 de septiembre de 2020). Mais 25 frigoríficos brasileiros recebem sinal verde da China. Valor Econômico., 10/9/2019 https://va-

lor.globo.com/agronegocios/noticia/2019/09/10/mais-25-frigorificos-do-brasil-recebem-o-sinal-verde-da-china.ghtml

MOTTA, L. (21 de octubre de 2020). Hoje o estoque de investimento chinês no Brasil é de cerca de U\$ 80 bilhões (Entrevista com o embaixador da China no Brasil, Yang Wanming). Isto é Dinheiro. https://www.istoedinheiro.com.br/hoje-o-estoque-do-investimento-chines-no-brasil-e-de-cerca-de-us-80-bilhoes/

NARCISO, B. (21 de febrero de 2020). Coronavírus afeta 60\% da indústria de eletroeletrônicos do Brasil, diz entidade. Folha de S. Paulo. https://www1.folha.uol.com.br/mercado/2020/02/coronavirus-afeta-60-da-industria-de-eletroeletronicos-do-brasil-diz-entidade.shtml

NATIONAL BUREAU OF STATISTICS OF CHINA. (13 de julio de 2020). China Statistical Yearbook 2016. http://www.stats.gov.cn/tjsj/ndsj/2016/indexeh.htm

PENNAFORT, R. (5 de noviembre de 2018) Países podem comprar no Brasil, mas não comprar o Brasil, diz Bolsonaro. O Estado de S. Paulo. https://economia.estadao.com.br/noticias/geral,paises-podem-comprar-no-brasil-mas-nao-comprar-o-brasil-diz-bolsonaro,70002587504

POLITO, R. (10 de octubre de 2020). Alvo de Bolsonaro, chineses têm 10\% da geração de energia no Brasil. Valor Econômico. 10/10/2018. https://valor.globo.com/empresas/noticia/2018/10/10/alvo-de-bolsonaro-chineses-tem-10-da-geracao-deenergia-no-brasil.ghtml

RIBEIRO, M. (2 de junio de 2029). China compra mais do Brasil e eleva participação na exportação para 40\%. Valor Econômico. https://valor.globo.com/brasil/noticia/2020/06/02/china-compra-mais-do-brasil-e-eleva-participacao-na-exportacao-para-40.ghtml

ROSITO, T. (25 de abril de 2020). O Plano Decenal 2022-2031: oportunidade de preparação e realinhamento. Carta Brasil-China. http://cebc.org.br/2020/04/28/o-planodecenal-brasil-china-2022-2031-oportunidade-de-preparacao-e-realinhamento/

SCOMAZZON, M. C. y FRANCO, J. Primeira Circum-Navegação Brasileira e Primeira Missão do Brasil à China (1879). Florianópolis: Dois por Quatro Editora, 2020. 
WANG, Q. y LU, W. (20 de marzo de 2020). Mutual respect prerequisite for China-Brazil cooperation: experts. Global Times. http://www.globaltimes.cn/content/1183201.shtml Acesso em 13/7/2020

WARTH, A. (13 de julio de 2020). Requisitos mínimos de segurança do $5 \mathrm{G}$ não restringem nem privilegiam empresas. O Estado de S. Paulo. https://economia.estadao.com.br/noticias/geral,requisitos-minimos-de-seguranca-do-5g-nao-restringem-nem-privilegiam-empresas,70003362694.

WIZIAK, J. (19 de noviembre de 2020). China pôs USȘ 100 bilhões de fundos à disposição do Brasil. Folha de S. Paulo. https://www1.folha.uol.com.br/mercado/2019/11/china-poe-us-100-bilhoes-de-fundos-a-disposicao-do-brasil.shtml

WIZIAK, J. E URIBE, G. (12 de junio de 2020). Bolsonaro transforma 5 G em disputa geopolítica, e leilão deve ficar para 2021. Folha de S. Paulo. https://www1.folha.uol.com.br/mercado/2020/06/bolsonaro-transforma-5gem-disputa-geopolitica-e-leilao-deve-ficar-para-2021.shtml 